19. Paniculae rami inferiores subquini semiverticillati; palea inferior suboblique truncato-vel rotundato-obtusa. 20 .

Paniculae rami inferiores subgemini; palea inferior oblusaaculiuscula. 21.

20. Paniculae laxae rami inferne longo tractu nedi demum reflexi; flosculi laxi; gluma inferior obtusa; palea inferior apice rotundala; folia firma acuminala:

G. distans $\mathrm{W}$ ahl $\mathrm{lb}$.

Paniculae confertae rami fere a basi spiculiferi erecto-patentes; flosculi approximati; gluma inferior obtusiuscula ; palea inf. truncata; folia mollia acula: $\quad G$. conferta F r.

21. Glumae acutiusculae; palea inferior obtusa: G. Gussonii Parl. Glumae rotundato-oblusae; palea inferior obtusiuscula:

Grosswardein, am 13. November 1864 .

G. permixta Guss.

\title{
Mittheilungen über zwei neue schweizerische Pflanzenarten.
}

Von Pfarer Münch.

Wie es im Allgemeinen im Interesse der Naturwissenschaften liegt, neue Entdeckungen zu veröffentlichen und zu verwerthen, so ist es zunächst auch auf dem Gebiete der Pflanzenforschung.

Diess veranlasst uns, über 2 interessante Pflanzenarten, welche in neverer Zeit in der Schweiz als Seltenheiten entdeckt wurden und die wir in unserm Herbar besilzen, folgende Eröffnungen zu machen.

1. Centaurea Kotschyana Heuffel. - Wurzel holzig, von alten Blattresten beschopft. Slengel $1-2^{\prime}$ hoch gefurcht, $1-3$ köpfig, unter den Köpfchen dicht befilzt. Die ersten Wurzelblätter in den Blattstiel verschmälert, länglich eirund ganzrandig oder kerbig gezähnt; die spätern gestielt, tief fiederspaltig, leierförmig, mit grossen, stumpfen Endlappen. Stengelblälter sitzend, fiederspaltig, am Grunde oft gefiedert, mil grossen, stumpfen Endlappen, oben kahl, an den Rücknerven rauh behaart.

Hauptkelch kugelig. Anhängsel der nervenlosen Blättchen dreiechig, spitz, braunschwarz, mit langen brannen, an der Spitze grauen, die halbrunden grünen Blättchen ganz deckenden Fransen. Köpfe in blühendem Zustande 2 Zoll im Durchmesser. Diese Köpfchen sind 2 bis 3 inal grösser als bei Cent. Scabiosa. - Blüthen violett, purpurn. Randblüthen tieflineal 5spaltig. - Scheibenblüthen purpurn. Narbe lang beflaumt. Samen weiss, schwach behaarl, so lange als der braune Schopf. Ausd. Juli - August.

Am südlichen Abhang der Schafmatt im Entlebuch über Alp Groen an der Fluh, Kanton Luzern. Bis jetzt einziger Standort für die Schweiz. 
Diese Cent. Kotschyana, deren Vorkommen auf alpine Höhcn beschränkt ist, wächst auch auf der Alp. Korongyis bei Radna im nördlichsten Siebenbüren und steht daselbst auf Gneis. Wir besitzen sie von den Alpen Siebenbürgens.

Sie hat grosse Aehnlichkeit mit C. alpestris Hag. welche auf den Alpen um St. Moritz in Graubünden häufig ist, wo sie im Juli und August mit ihren grossen, purpurrothen Blumen eine Zierde der Wiesen bildet.

2. Calla palustris L. - Rhizom dick, lang, kriechend gegliedert, mit weissen Fasern besetzt. Stengel 1 Fuss hoch, aufstrebend. Blätter wurzelständig, aus dem Rücken einer - die Wurzel oder den Stengel umschliessenden - Scheide entspringend, lang gestielt, gross, herzeiförmig, pfriemlich zugespitzt, ganzrandig, glänzend, oben etwas concav, Blattscheide mit 2 Oelirchen den Kolbenstiel umfassend, dann eiförmig flach ausgebreitet, in eine pfriemliche Spitze auslaufend, aussen grün, innen schneeweiss bei der Blüthe, später auch grün. Kolben endständig gestielt, walzlich, ganz mit einzelnen von $4-6$ Staubgefässen umgebenen Fruchtknoten besetzt. Perigon fehlt. Beeren erst grün, dann hochroth, $5-7$ linig.

In Sumpf- und Abzugsgräben des Chrüstirainwaldes bei Sempach Kanton Luzern. Einziger bisanhin bestimmter Standort für die Schweiz.

Der von Schleicher bezeichnete Standort am Lac de Joux, K. Waadt hat sich längst als eine Täuschung erwiesen.

Ausd. Juli, August.

Basel im November 1864 .

\section{Correspondenz.}

Innsbruck, den 14. December 186h.

Sie finden unter der diessmaligen Sendung auch Chantransia thermalis und Prasiola Sauteri K $\mathrm{zg}$., zwei Algen, auf welche ich besonders aufmerksam machen will. Die erstere fand sich einzig und allein an den Kalktuffabsälzen in den warmen Quellen $\left(26^{\circ}\right.$ R. $)$ des Kaiserbades bei Ofen und ist jetzt, nachdem man den Fundort gănzlich verbaut und die Quellen gefasst hat, verschwunden und wahrscheinlich für immer als ausgestorben zu betrachten. Die Prasiola Sauteri entdeckte ich in einer Quelle, deren Temperatur am 26. Juli $0^{\circ} .8 \mathrm{R}$. betrug und die an der NW. Seite des Plerchnerkammes, eines Felsenriffes, welcher die Eismassen des Lisenser Ferners nach Osten begrenzt und die Wasserscheide zwischen dem tirolischen Stubaier und Selrainer Thal bildet, hervorsprudelt. Dieser Standort scheint mir ein ganz besonderes Interesse in Anspruch zu nehmen. Die Gebr. Schlagintweil gaben nämlich als die höchste in den Alpen bisher bekannt gewordene zu Tag tretende Quelle jene an der Salmshöhe bei 